\title{
Outbreak of growth anomalies in coral communities of Qeshm Island, Persian Gulf
}

\author{
Pavriz Tavakoli-Kolour • Javid Kavousi • \\ Hamid Rezai
}

Received: 11 November 2014/ Accepted: 20 March 2015/Published online: 2 April 2015

(C) The Author(s) 2015. This article is published with open access at Springerlink.com

\begin{abstract}
Reports on the outbreaks of coral diseases are on the rise, stating that diseases are considered to be one of the main drives in the decline of global coral reefs. In this study, the outbreak of growth anomalies (GAs) in coral communities of the south of Qeshm Island in the Persian Gulf is reported. Despite a previous report on the localized GAs on a few colonies, this is the first report of GA outbreak from the Persian Gulf, in which $28 \pm 11 \%( \pm \mathrm{SE})$ and $21 \pm 13 \%$ of $P$. daedalea and Porites colonies contracted GAs in July 2012. A year later, we recorded GAs on $37 \pm 07 \%$ of P. daedalea and $23 \pm 12 \%$ of Porites colonies. Pearson's correlation test showed a strong positive relationship between coral colony size and the number of GAs $(r=0.907, p<0.05)$. Further investigation is needed to understand the cause of GAs, their progress trend, and prospective impacts on the coral communities at our studied site.
\end{abstract}

Keywords Disease · Growth anomalies · Massive Porites · Persian Gulf

\section{Introduction}

Coral diseases are known as one of the most prevalent threats to coral reefs worldwide (Sutherland et al. 2004; Weil et al. 2006). In the recent years, reports on coral diseases and subsequent mass mortalities have increased worldwide (Goreau et al. 1998; Green and Bruckner 2000; Sutherland et al. 2004; Weil et al. 2006). Although the Caribbean Sea is considered the main coral disease hot spot with over $66 \%$ of the world's recorded diseases (Green and Bruckner 2000), Indo-Pacific coral reefs are getting more attention due to increasing instances of coral disease outbreaks recently (e.g., Willis et al. 2004; Weil et al. 2012) and the Persian Gulf is no exception (Riegl et al. 2012).

Although coral disease studies in the southern Persian Gulf started about two decades ago (see Riegl et al. 2012), little information was available on coral diseases of the northern part until recently. Except the Yellow Band Disease, which was reported at two Iranian Islands in 2000 and 2002 (Rezai et al. 2004), the other

P. Tavakoli-Kolour $(\bowtie)$

Young Researchers and Elite Club, Bandar Abbas Branch, Islamic Azad University, PO Box 79159-14 1311, Bandar Abbas,

Iran

e-mail: p.tavakoli@hotmail.com

J. Kavousi

Graduate School of Engineering and Science, University of the Ryukyus, 1 Senbaru, Nishihara, Okinawa 903-0213, Japan

H. Rezai

Iranian National Institute for Oceanography and Atmospheric Sciences, Tehran, Iran 
reports on diseases were drawn up only in the last few years (Samimi-Namin et al. 2010; Kavousi and Rezai 2011; Kavousi et al. 2013).

Similarly, serpulid invasions associated with red tides at Qeshm Island (Samimi-Namin et al. 2010) and the White Mat Disease at Hormuz Island (Kavousi et al. 2013) caused mass coral mortalities in the northern Persian Gulf. Other reports included growth anomalies (GAs) only on a few colonies at Larak, Hengam, and southeast of Qeshm Island (Kavousi and Rezai 2011). However, no coral colonies with GAs were observed at the southern part of Qeshm Island. Here, we report the outbreak of GAs in Platygyra daedalea and Porites spp. colonies as the only coral taxa affected among the southern coral communities of Qeshm Island in 2012 and 2013.

\section{Materials and methods}

The study site includes the southern coral communities of Qeshm Island $\left(26^{\circ} 45^{\prime} \mathrm{N}, 55^{\circ} 49^{\prime} \mathrm{E}\right.$, Fig. 1) in the Persian Gulf. The present investigation took place during July 2012 and July-August 2013. In total, eight $30 \mathrm{~m}^{-1}$ Line-Intercept transects were established at depth $2-5 \mathrm{~m}^{-1}$ in each year for preliminary assessment of benthic communities including live coral and coral genera cover. Moreover, to study growth anomalies (GAs) dynamic on the affected corals, eight $30 \mathrm{~m}^{-2}$ belt transects were considered. Coral skeletons in GAs and healthy parts of coral colonies were observed under a focal microscope to check out the microstructural differences.

Furthermore, during 2013, 11 colonies of Platygyra daedalea with GAs were measured in three dimensions (length, width, and height) and the frequency of GAs were counted followed by the Pearson's correlation test to assess whether there was any relationship between coral colony size and the number of GAs in coral colonies. Porites colonies were not considered due to the negligible difference in their size.

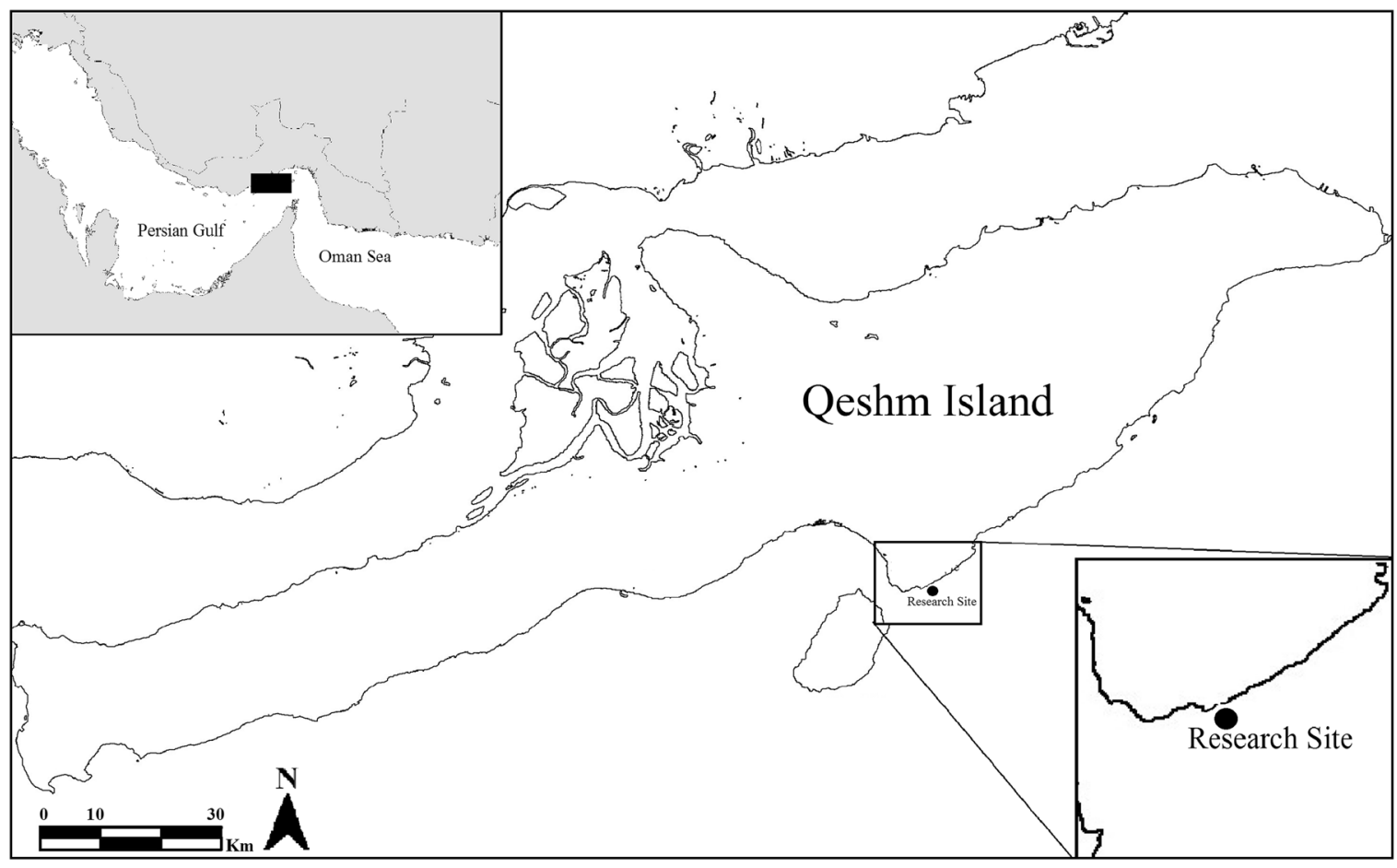

Fig. 1 Map of the site studied in this research 


\section{Results and discussion}

Live coral cover

Live coral constituted $20 \%$ of the substrate of the studied site at Qeshm Island (Fig. 2), which is higher than that reported for 2009, $14.03 \pm 4.8 \%$ (Kavousi et al. 2011). Platygyra daedalea, as the dominant coral taxa, accounts for approximately $50 \%$ of the live coral cover in the area ( $\sim 3 \%$ in 2012 and $~ 49 \%$ in 2013; Fig. 3). In contrast, Porites spp. as dominant genus in the southeast of Qeshm Island constituting $89 \pm 12.2 \%$ (Kavousi et al. 2011) accounts for about $6 \%$ of the coral cover at the current studied site (Fig. 3).

Growth anomalies (GAs) on corals

P. daedalea and Porites spp. were the only coral taxa with GAs (Fig. 4). GAs accounted for $28 \pm 11 \%$ $( \pm \mathrm{SE})$ and $21 \pm 13 \%$ in P. daedalea and Porites colonies, respectively, during July 2012, whereas they were $37 \pm 07 \%$ and $23 \pm 12 \%$ in P. daedalea and Porites spp., respectively (Fig. 5). These results show a $9 \%$ increase in GAs on P. daedalea colonies, but the increase in Porites spp. is negligible. Although localized GAs on P. daedalea and Dipsastraea (formerly Favia) were recorded at Iranian Islands (Kavousi and Rezai 2011), GA outbreak has never been previously reported for the Persian Gulf.

There is a highly positive correlation between the coral colony size and the number of GAs $(r=0.907$, $p<0.05$, Fig. 6). In other words, the bigger the colony, the greater the chances of GAs. Irikawa et al. (2011) also found that Acropora cytherea colonies larger than $120 \mathrm{~cm}$ in diameter had more GAs at some Japanese reefs. Loya et al. (1984) studying GAs in two species of Platygyra at some Australian reefs found that the larger the colony, more likely it is to have GAs.

Microscopic photographs of the coral skeletons show that calices of the affected areas are irregular, destructed, and bigger than those of normal coral skeletons (Fig. 7). Similar results are reported in other studies (McClanahan et al. 2009; Irikawa et al. 2011; Stimson 2011).

Fig. 2 Percentages of biotic and abiotic objects at the studied site. $L C$ live coral, $D C$ dead coral, $R b$ rubble, $S d$ sand, $R c$ rock, $A l$ algae, $S p$ sponge

Fig. 3 Coral genera coverage at the studied site
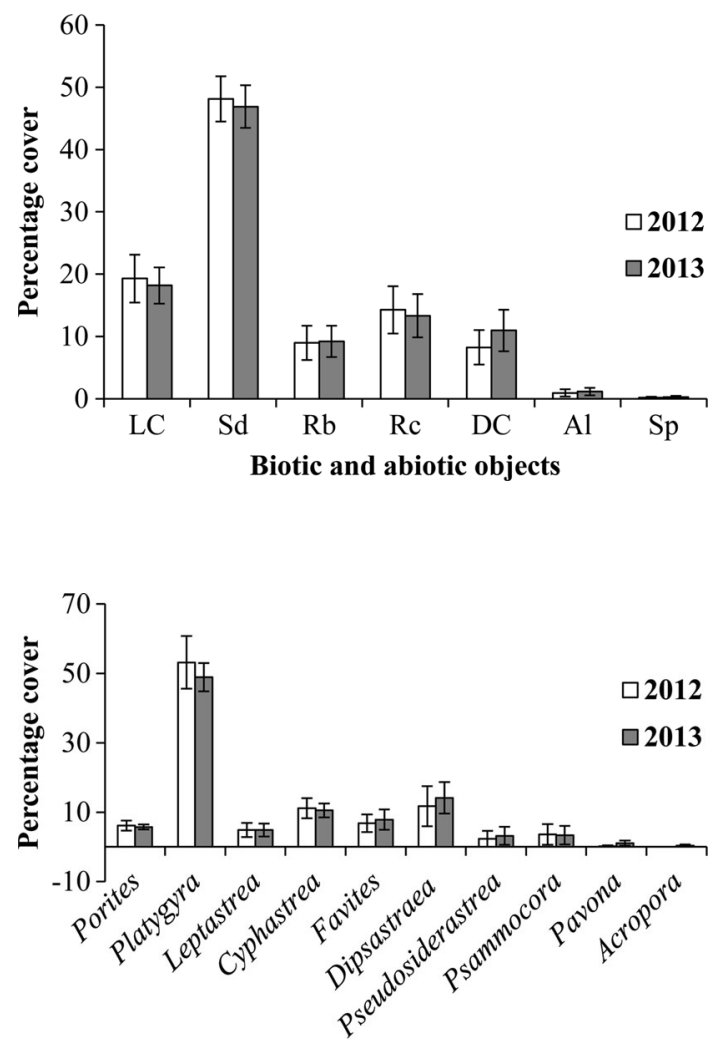

Coral genera 
Fig. 4 Growth anomalies on Platygyra daedalea (a) and on Porites spp. (b)

Fig. 5 Percentage of coral colonies contracting growth anomalies in 2012 and 2013

Fig. 6 The relationship between Platygyra daedalea colony size and the frequency of growth anomalies in 2013

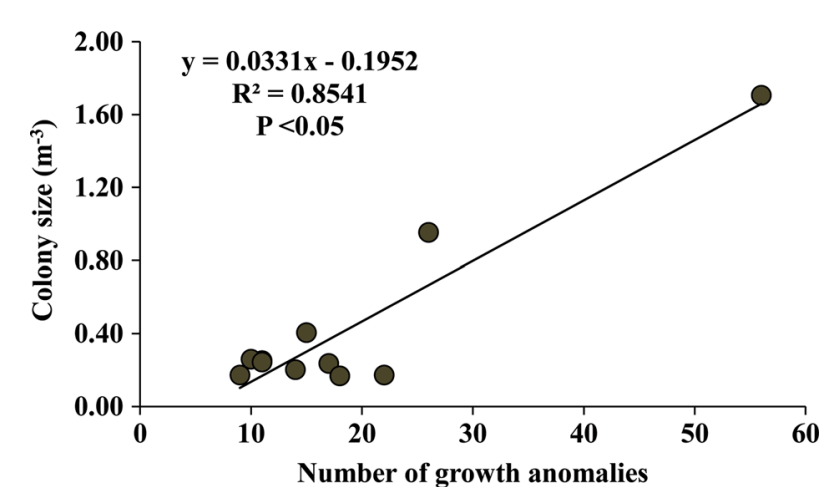

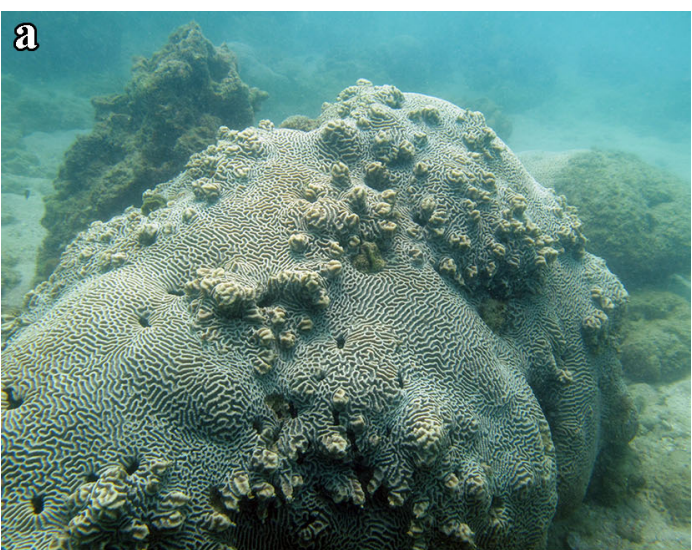
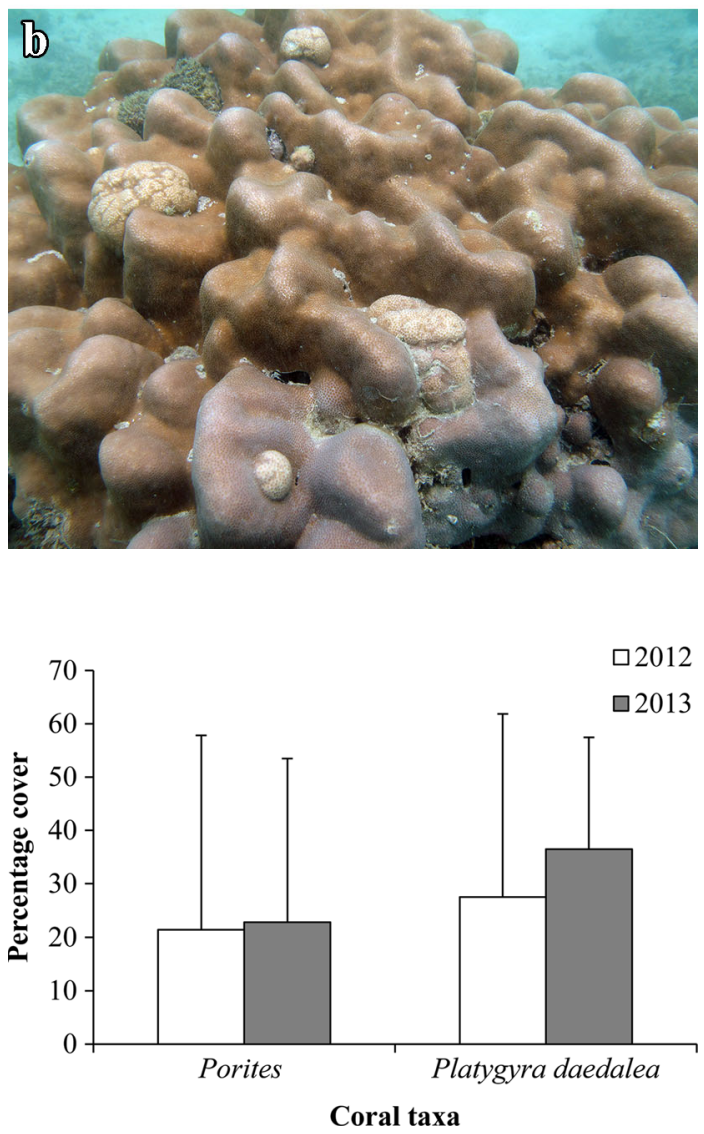

Coral taxa 

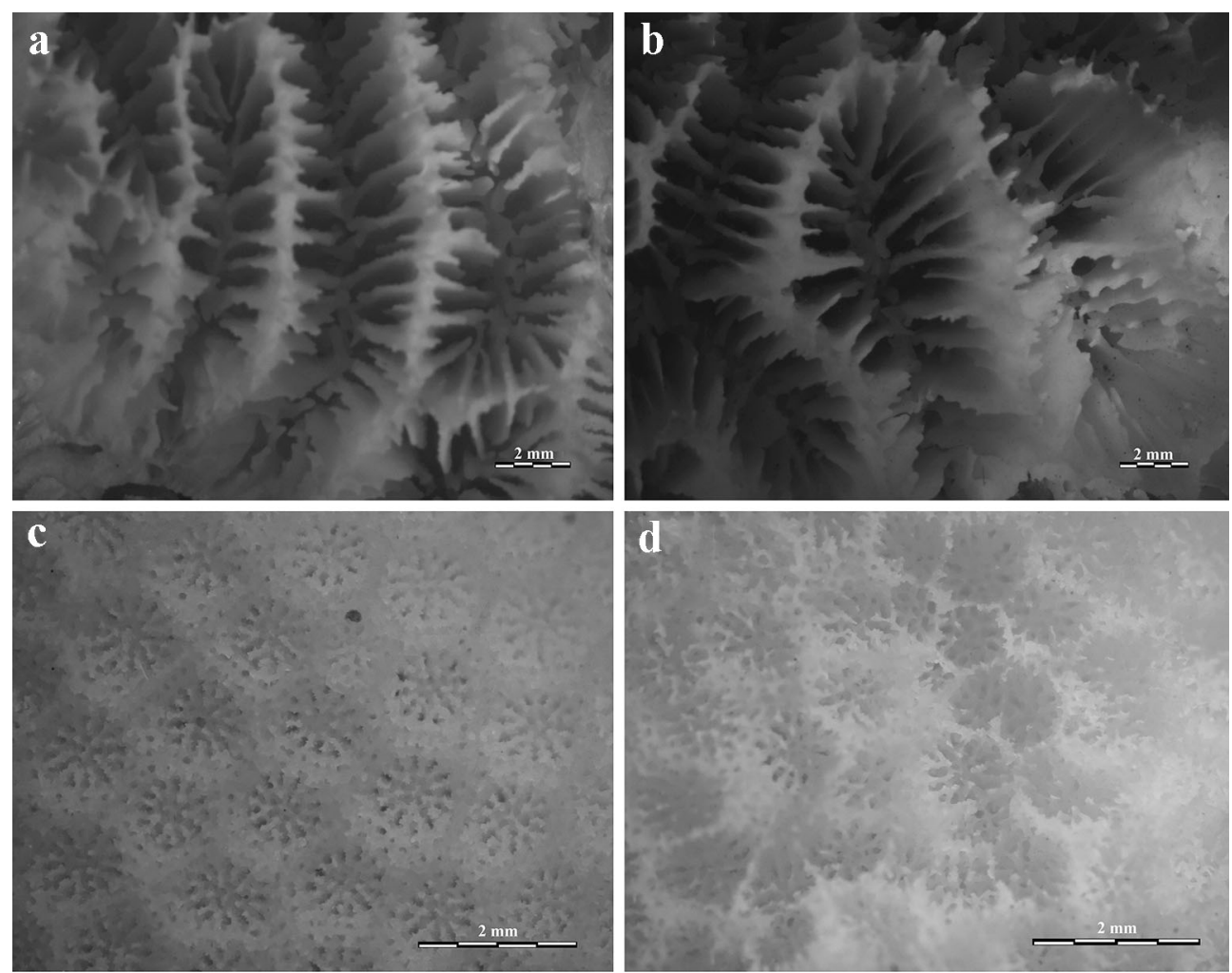

Fig. 7 Microscopic photographs of the coral skeletons of a healthy and $\mathbf{b}$ GA parts of Platygyra daedalea, $\mathbf{c}$ healthy, and $\mathbf{d}$ GA parts of Porites spp.

Although the etiology of GAs, like the majority of coral diseases, is understudied, environmental factors have been suggested as the main cause. For example, McClanahan et al. (2009) found a strong relationship between Porites growth anomalies and coral bleaching at Kenyan coral reefs. As a massive bleaching happened in the northern Persian Gulf, extending to our studied site in 2012 (Kavousi et al. 2014), high temperatures might have been a cause of GAs in this area. However, it is unlikely that anomalous temperatures alone could be the cause of the GA outbreak because no GAs were observed at other sites encountering mass bleaching in the area at the same time.

Irikawa et al. (2011) monitoring some Japanese reefs for 10 years suggested that GAs on Acropora cytherea were a resultant of aging amplified by temperature anomalies. Some studies also suggested biotic factors such as viruses, fungi, and endolithic algae as the cause of GAs (see Weil et al. 2012). McClanahan et al. (2009) mentioned that altered calice structure in GA areas is due to some microbioeroders including fungi causing the unusual growth.

Another study found that environmental conditions together with the human population size as well as the abundance of host coral communities strongly influence Acropora and Porites GA prevalence in the IndoPacific (Aeby et al. 2011). Our research site, however, encompasses a local community with a few boats, which are used for limited fishing and transportation, it is not close to ports, industrial complexes, or urban areas. The suggestion by Aeby et al. (2011) may not hold true for our studied zone as not only the stressors including human pressure are relatively greater in number at the southeast of Qeshm Island but also Porites spp. are dominant ( $\sim 89 \%)$ at that site (Kavousi et al. 2011). However, no GA outbreak was discerned in that site (pers. obs.). We hypothesize that a compulsory combination of environmental conditions, host corals' physiological conditions, and microbial invasions may determine occurrence and development of GAs on corals. Partial involvement of the mentioned factors may explain why some studies report transition of GAs to healthy colonies (Kaczmarsky and Richardson 2007), whereas others do not (Irikawa et al. 2011). However, the certain cause of the observed outbreak of the GAs at the south of Qeshm Island remains unknown for the time being. 
Although GAs do not kill coral colonies, they can decrease fecundity in the affected parts (Irikawa et al. 2011). Therefore, if an increasing trend in the outbreak of GAs on coral colonies is observed for a long term, so that GAs can cover most of the coral colony surface, it may decline coral recovery after disturbances because of insufficient recruits. The case may be more serious for our studied site as it encounters continuous stressors (Kavousi et al. 2011, 2014). Therefore, it is necessary to conduct field experiments to understand the dynamics and future impacts of GAs on coral communities of the south of Qeshm Island.

Open Access This article is distributed under the terms of the Creative Commons Attribution License which permits any use, distribution, and reproduction in any medium, provided the original author(s) and the source are credited.

\section{References}

Aeby GS, Williams GJ, Franklin EC, Haapkyla J, Harvell CD, Neale S, Page CA, Raymundo L, Vargas-Ángel B, Willis B, Work TM, Davy SK (2011) Growth anomalies on the coral genera Acropora and Porites are strongly associated with host density and human population size across the Indo-Pacific. PLoS One 6:e16887. doi:10.1371/journal.pone.0016887

Goreau TJ, Cervino J, Goreau M, Hayes R, Hayes M, Richardson L, Smith G, DeMeyer K, Nagelkerken I, Garzon-Ferrera J, Gil D, Garrison G, Williams EH, Bunkley-Williams L, Quirolo C, Patterson K, Porter JM, Porter K (1998) Rapid spread of diseases in Caribbean coral reefs. Rev Biol Trop 46:157-171

Green EP, Bruckner AW (2000) The significance of coral disease epizootiology for coral reef conservation. Biol Cons 96:347-361. doi:10.1016/S0006-3207(00)00073-2

Irikawa A, Casareto BE, Suzuki Y, Agostini S, Hidaka M, van Woesik R (2011) Growth anomalies on Acropora cytherea corals. Mar Poll Bull 62(8):1702-1707. doi:10.1016/j.marpolbul.2011.05.033

Kaczmarsky L, Richardson LL (2007) Transmission of growth anomalies between Indo-Pacific Porites corals. J Invertebr Pathol 94(3):218-221. doi:10.1016/j.jip.2006.11.007

Kavousi J, Rezai H (2011) Coral lesions around some Iranian Islands in the Persian Gulf. Galaxea 13:5-6

Kavousi J, Seyfabadi J, Rezai H, Fenner D (2011) Coral reefs and communities of Qeshm Island, the Persian Gulf. Zool Stud 50:276-283

Kavousi J, Tavakoli-Kolour P, Barkhordari A, Bahrami A (2013) Mass mortality of Porites Corals on northern Persian Gulf reefs due to sediment-microbial interactions. Int J Mar Sci 3:306-310. doi:10.5376/ijms.2013.03.0038

Kavousi J, Tavakoli-Kolour P, Mohammadizadeh M, Bahrami A, Barkhordari A (2014) Mass coral bleaching in the northern Persian Gulf, 2012. Sci Mar 78(3):397-404. doi:10.3989/scimar.03914.16A

Loya Y, Bull G, Pichon M (1984) Tumor formations in scleractinian corals. Helgol Mar Res 37:99-112. doi:10.1007/BF01989297

McClanahan TIM, Weil E, Maina J (2009) Strong relationship between coral bleaching and growth anomalies in massive Porites. Gobal Change Biol 15:1804-1816

Rezai H, Wilson S, Claereboudt M, Riegl B (2004) Coral reef status in the ROPME sea area, Arabian/Persian Gulf, Gulf of Oman and Arabian Sea. In: Wilkinson C (ed) Status of coral reefs of the world, vol 1. Australian Institute of Marine Science, Washington DC, USA, pp 155-170

Riegl BM, Bruckner AW, Samimi-Namin K, Purkis SJ (2012) Diseases, harmful algae blooms (HABs) and their effects on Gulf coral populations and communities. In: Riegl BM, Purkis SJ (eds) Coral reefs of the Gulf. Springer, Netherlands, pp 107-125

Samimi-Namin K, Risk MJ, Hoeksema BW, Zohari Z, Rezai H (2010) Coral mortality and serpulid infestations associated with red tide, in the Persian Gulf. Coral Reefs 29:509. doi:10.1007/s00338-010-0601-x

Stimson J (2011) Ecological characterization of coral growth anomalies on Porites compressa in Hawaii. Coral Reefs 30(1):133-142. doi:10.1007/s00338-010-0672-8

Sutherland KP, Porter JW, Torres C (2004) Disease and immunity in Caribbean and Indo-Pacific zooxanthellate corals. Mar Ecol Prog Ser 266:273-302. doi:10.3354/meps266273

Weil E, Smith GW, Gil-Agudelo DL (2006) Status and progress in coral reef disease research. Dis Aquat Org 69:1-7. doi:10. 3354/dao069001

Weil E, Irikawa A, Casareto B, Suzuki Y (2012) Extended geographic distribution of several Indo-Pacific coral reef diseases. Dis Aquat Org 98(2):163-170. doi:10.3354/dao02433

Willis BL, Page CA, Dinsdale EA (2004) Coral disease on the Great Barrier Reef. In: Rosenberg E, Loya Y (eds) Coral health and disease. Springer, Berlin, pp 69-104 